\title{
Lenvatinib in elderly hepatocellular carcinoma patients, a new therapeutic option in first line
}

\author{
Gael S. Roth ${ }^{1,2,3}$, Bleuenn Brusset ${ }^{1,2,3}$, Thomas Decaens ${ }^{1,2,3}$ \\ ${ }^{1}$ Faculté de médecine, Université Grenoble Alpes, Grenoble, France; ${ }^{2}$ Clinique Universitaire d'Hépato-gastroentérologie, Pôle Digidune, CHU \\ Grenoble, France; ${ }^{3}$ Institute for advanced biosciences-INSERM U1209/CNRS UMR 5309/Université de Grenoble-Alpes, Grenoble, France \\ Correspondence to: Thomas Decaens. Faculté de médecine, Université Grenoble Alpes, Grenoble, France; Clinique Universitaire d’Hépato- \\ gastroentérologie, Pôle Digidune, CHU Grenoble, France; Institute for advanced biosciences - INSERM U1209 / CNRS UMR 5309 / Université \\ de Grenoble-Alpes, Grenoble, France. Email: tdecaens@chu-grenoble.fr. \\ Comment on: Tada T, Kumada T, Hiraoka A, et al. Safety and efficacy of lenvatinib in elderly patients with unresectable hepatocellular carcinoma: A \\ multicenter analysis with propensity score matching. Hepatol Res 2020;50:75-83.
}

Submitted Apr 20, 2020. Accepted for publication May 07, 2020.

doi: $10.21037 /$ atm-20-3440

View this article at: http://dx.doi.org/10.21037/atm-20-3440

Liver cancer is the second leading cause of cancerrelated death with approximately 750,000 new cases of hepatocellular carcinoma (HCC) per year worldwide (1). The diagnosis remains late and only $30 \%$ of patients have access to curative treatment at the time of diagnosis $(2,3)$. In palliative setting, until recently, only Sorafenib, a multityrosine kinase inhibitor, was validated in first line. Sorafenib allows an overall survival of 10.7 versus 7.9 months with placebo since the SHARP study in 2008 (4). Since then, multiple therapies have failed in first line phase 3 trials versus sorafenib. In 2018, Lenvatinib, another multi-tyrosine kinase inhibitor targeting VEGF receptors 1-3, FGF receptors $1-4$, PDGF receptor $\alpha$, RET, and KIT, showed promising results in a non-inferiority phase 3 trial (5). Lenvatinib met non-inferiority criteria with a median survival time of 13.6 months compared to 12.3 months with sorafenib (hazard ratio $0.92,95 \% \mathrm{CI}, 0.79-1.06$ ). The most common adverse events with lenvatinib were hypertension (42\%), diarrhoea (39\%), anorexia (34\%), and loss of weight (31\%). This toxicity profile seems to be more tolerable compared to sorafenib one from a patient perspective. Second line treatments are approved after intolerance and/or progression under Sorafenib. Lenvatinib is thus a good option in first line treatment of advanced HCC.

Nowadays, hepatocellular carcinoma incidence is constantly increasing as well as worldwide population age, suggesting that treatment of HCC elderly patients constitutes a major public health issue. However, few data are available in phase 3 trials concerning this fragile population as illustrated by the recent non-inferiority phase 3 assessing lenvatinib, where only $13 \%$ of patient were older than 75 . In an original retrospective study published in Hepatology Research, Tada et al. showed that lenvatinib can be used safely and efficaciously in a cohort of HCC patients composed of 50 elderly patients ( $>75$ years) and 50 non elderly patients using propensity score. In this work, lenvatinib showed comparable progression free survival and overall survival regardless of patients' age, as well as similar safety profile. Most frequent adverse events of any grade in elderly patients were fatigue $(36.0 \%)$, anorexia $(26.0 \%)$, hypothyroidism $(24.0 \%)$, proteinuria $(22.0 \%)$, palmar-plantar erythrodysesthesia $(22.0 \%)$, and hypertension (20.0\%). Twelve percent of elderly patients experienced grade 3-4 fatigue. Nonetheless, lenvatinib dose was significantly lower in elderly group with only $28 \%$ of patients treated at a $12 \mathrm{mg}$ dose versus $64 \%$ of non-elderly patients. This lower dose doesn't seem to be related to lower weight because BMI was not significantly lower in elderly population. This suggests that this population needs specific treatment adaptations.

Besides, Tada et al. proposed a correlation between occurrence of palmoplantar erythrodysesthesia and a better overall survival. Nonetheless, this type of analyses classically were already controversial in sorafenib cohorts as they suffer from biases such as the duration of exposure, the drug dose and the observance, that constitute parameters influencing both the frequency of this adverse event and the survival. This analysis wonders 
specific statistical analysis. Thus, these results should be interpreted with caution, especially in a retrospective study with such small groups.

This study offers interesting safety and efficacy data on lenvatinib in an elderly advanced HCC patients, a frequent population that is rarely represented in clinical trials, at a time where well tolerated and promising therapies such as anti-programmed death (PD)-1 inhibitors failed to prove a benefit in phase 3, letting HCC patients with still very few options in first line.

\section{Acknowledgments}

Funding: None.

\section{Footnote}

Provenance and Peer Review: This article was commissioned by the editorial office, Annals of Translational Medicine. The article did not undergo external peer review.

Conflicts of Interest: All authors have completed the ICMJE uniform disclosure form (available at http://dx.doi. org/10.21037/atm-20-3440). All authors have no conflicts of interests to declare.

Ethical Statement: The authors are accountable for all aspects of the work in ensuring that questions related to the accuracy or integrity of any part of the work are appropriately investigated and resolved.

Cite this article as: Roth GS, Brusset B, Decaens T. Lenvatinib in elderly hepatocellular carcinoma patients, a new therapeutic option in first line. Ann Transl Med 2020;8(21):1335. doi: 10.21037/atm-20-3440
Open Access Statement: This is an Open Access article distributed in accordance with the Creative Commons Attribution-NonCommercial-NoDerivs 4.0 International License (CC BY-NC-ND 4.0), which permits the noncommercial replication and distribution of the article with the strict proviso that no changes or edits are made and the original work is properly cited (including links to both the formal publication through the relevant DOI and the license). See: https://creativecommons.org/licenses/by-nc-nd/4.0/.

\section{References}

1. Ferlay J, Soerjomataram I, Dikshit R, et al. Cancer incidence and mortality worldwide: sources, methods and major patterns in GLOBOCAN 2012. Int J Cancer. 2015;136:E359-86.

2. European Association For The Study Of The Liver; European Organisation For Research And Treatment Of Cancer. EASL-EORTC clinical practice guidelines: management of hepatocellular carcinoma. J Hepatol 2012;56:908-43.

3. Llovet JM, Zucman-Rossi J, Pikarsky E, et al. Hepatocellular carcinoma. Nat Rev Dis Primers 2016;2:16018.

4. Llovet JM, Ricci S, Mazzaferro V, et al. Sorafenib in advanced hepatocellular carcinoma. $\mathrm{N}$ Engl J Med 2008;359:378-90.

5. Kudo M, Finn RS, Qin S, et al. Lenvatinib versus sorafenib in first-line treatment of patients with unresectable hepatocellular carcinoma: a randomised phase 3 noninferiority trial. Lancet 2018;391:1163-73. 